\title{
Erector spinae plane block for back surgery
}

\author{
Maiko Satomoto $^{1} \cdot$ Yushi U. Adachi $^{2} \mathbb{0}$
}

Received: 2 September 2021 / Accepted: 7 September 2021 / Published online: 17 September 2021

(c) Japanese Society of Anesthesiologists 2021

\section{To the Editor:}

We read with great interest the article published by Yörükoğlu et al. in the Journal of Anesthesia [1]. They evaluated supplemental erector spinae plane block (ESPB) in patients with lumbar disc herniation undergoing microdiscectomy. They also compared the effectiveness of ESPB to that of standard anesthesia in terms of morphine use in the acute postoperative period. The results of this study were easy to understand and appropriately described. Ultrasoundguided ESPB is being increasingly used for multimodal management of perioperative pain all over the world [2].

The study by Yörükoğlu et al. raised a fundamental question: is there a need for bilateral ESPB during this back surgery? The study recruited 60 participants undergoing singlelevel lumbar microdiscectomy. Less invasive back surgery is preferable for early recovery and reduced pain. Advanced surgeries, such as full-endoscopic interlaminar lumbar discectomy, are performed under regional instead of general anesthesia [3]. Microdiscectomy involves peeling off the erector muscles from the vertebrae in the supine position under general anesthesia. However, surgical manipulation is limited to the side of the incision, which reduces the pain and invasiveness of the procedure. Conversely, standard fusion surgery requires bilateral surgical manipulation.

If ESPB is applied only on the surgical side, the dose of local anesthetic could be increased at this site without the local anesthetic toxicity. Increasing the anesthetic dose

This comment refers to the article available online at https://doi. org/10.1007/s00540-021-02920-0.

Yushi U. Adachi

yushi.adachi@gmail.com

1 Department of Anesthesiology, Toho University Omori Medical Center, 6-11-1 Omori-Nishi, Ota-ku, Tokyo 1438541, Japan

2 Department of Emergency Medicine, Shizuoka Saiseikai General Hospital, 1-1-1 Oshika, Suruga-ku, Shizuoka 4228527, Japan or the injection volume may result in wide the analgesic area (e.g., during multi-level ESPB) [4]. One of the most significant advantages of regional anesthesia is that the area and duration of analgesia can be modified by changing the anesthetic volume or using a supplemental catheter.

ESPB, a novel technique, may be appropriate for managing perioperative pain in patients undergoing lumbar spine surgery from the perspective of anatomical approaching [5]. Further studies are required to confirm the effectiveness and safety of ESPB.

Funding None.

\section{Declarations}

Conflict of interest The authors declare that they have no competing interest.

\section{References}

1. Yörükoğlu HU, İçli D, Aksu C, Cesur S, Kuş A, Gürkan Y. Erector spinae block for postoperative pain management in lumbar disc hernia repair. J Anesth. 2021;35:420-5.

2. van den Broek RJC, van de Geer R, Schepel NC, Liu WY, Bouwman RA, Versyck B. Evaluation of adding the Erector spinae plane block to standard anesthetic care in patients undergoing posterior lumbar interbody fusion surgery. Sci Rep. 2021;11:7631.

3. Ünsal UU, Şentürk S. Comparison of direct costs of percutaneous full-endoscopic interlaminar lumbar discectomy and microdiscectomy: results from Turkey. Ideggyogy Sz. 2021;74:197-205.

4. Balaban O, Aydın T. Ultrasound guided bi-level erector spinae plane block for pain management in Herpes Zoster. J Clin Anesth. 2019;52:31-2.

5. Liu MJ, Zhou XY, Yao YB, Shen X, Wang R, Shen QH. Postoperative analgesic efficacy of erector spinae plane block in patients undergoing lumbar spinal surgery: a review and meta-analysis. Pain Ther. 2021;10:333-47.

Publisher's Note Springer Nature remains neutral with regard to jurisdictional claims in published maps and institutional affiliations. 